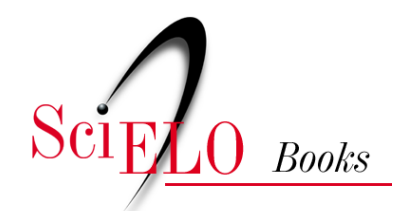

\title{
4. Mutações em curso no território fluminense A participação dos investimentos chineses no processo de reestruturação do território fluminense
}

\author{
Thiago Jeremias Baptista
}

\section{SciELO Books / SciELO Livros / SciELO Libros}

BAPTISTA, T.J. A participação dos investimentos chineses no processo de reestruturação do território fluminense. In: PENALVA, A., CORREIA, A.F., MARAFON, G.J., and SANT'ANNA, M.J.G., eds. Rio de Janeiro: uma abordagem dialógica sobre o território fluminense [online]. Rio de Janeiro: EdUERJ, 2018, pp. 388-412. ISBN 978-85-7511-476-6.

https://doi.org/10.7476/9788575115169.0016.

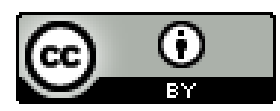

All the contents of this work, except where otherwise noted, is licensed under a Creative Commons Attribution 4.0 International license.

Todo o conteúdo deste trabalho, exceto quando houver ressalva, é publicado sob a licença Creative Commons Atribição $\underline{4.0}$.

Todo el contenido de esta obra, excepto donde se indique lo contrario, está bajo licencia de la licencia Creative Commons $\underline{\text { Reconocimento } 4.0 .}$. 


\section{A participação dos investimentos chineses no processo de reestruturação do território fluminense}

Thiago Jeremias Baptista

\section{Introduçáo}

A dimensão econômica do processo de globalização está relacionada a fenômenos que têm se intensificado nos últimos anos como, por exemplo, o aumento da concorrência e da integraçáo dos mercados, assim como a expansão dos fluxos internacionais de bens, serviços e capitais (Lacerda, 2000). Na escala global, o aumento na circulação dos fluxos de investimentos externos diretos $^{\mathrm{I}}$ (IED) nas últimas décadas contribuiu para um salto de, aproximadamente, US\$ 650 bilhóes, ao final da década de 1990, para US\$ I,76 trilhão, em 2015.

Durante esse período, a República Popular da China se destacou, não somente como recipiendária de investimentos externos na Ásia Oriental, mas também como um país que vem promovendo a internacionalização de seus investimentos. Segundo Cepal (2017), ela apresentou aumento sustentado de seus investimentos no exterior, alcançando a segunda posição enquanto origem de IED mundial (depois dos Estados Unidos). Nesse sentido, faz-se necessário destacar que os fluxos de IED chineses saltaram de US\$830 milhóes, em I990, para US\$ I27 bilhóes, em 20I5, ${ }^{2}$ alcançando US \$ I83, I bilhóes, em 2016 (Cepal, 20I7).

Nesse recorte temporal, o Brasil, em virtude da reforma administrativa realizada a partir da década de I990, caracterizou-se por um conjunto de mudanças em sua administração pública, consolidando o modelo gerencial orientado pelo

\footnotetext{
I. "Por investimento direto, entende-se o realizado em país estrangeiro, onde a parte investidora (corporação, empresa) detém o controle do próprio. Surge tipicamente sob a forma de uma subsidiária de uma empresa estrangeira, ou quando esta assume o controle de uma firma já existente no país em questāo” (Södersten, I979, p. 427).

2. UNCTAD (Conferência das Naçôes Unidas sobre Comércio e Desenvolvimento - sigla em inglês). Disponível em: http://unctadstat.unctad.org/wds/TableViewer/tableView.aspx. Acesso em: Io jun. 2017.
} 
neoliberalismo, ${ }^{3}$ cujas bases se assentaram em pilares como a modernização, a privatização e a abertura ao capital estrangeiro (Tenório e Saraiva, 2006; Andrews, 20IO; Castro, 20I6; Giambagi; 20I6). Como resultado, a maior economia sul-americana apresentou uma trajetória de ampliação como recipiendária de investimentos externos diretos, implicando o aumento da participação do IED no PIB nacional (Alves, 20I4).

A dimensão acerca do processo de aumento do influxo de capitais estrangeiros no Brasil nos últimos anos pode ser entendida quando notamos a sua passagem da condição de receptor de US\$392 milhóes, em I970, para recipiendário de US $\$ 989$ milhóes, em I990, alcançando US $\$ 96$, I bilhôes na recepção de IED, em 20II. Apesar da entrada de capitais estrangeiros ter se retraído recentemente, dada a recepção de US\$ 64,6 bilhôes, em $2015,{ }^{4}$ o país ainda mantém posição relevante entre os receptores de investimentos externos na regiáo.

Nesse primeiro quarto de décadas do século XXI, paralelo ao processo de influxo capitais estrangeiros no território nacional, tem ocorrido a ampliação de investimentos chineses no Brasil. Estabelecendo uma nova fase no âmbito das relaçóes sino-brasileiras, a República Popular da China não somente aumentou sua participação enquanto destino das exportaçôes brasileiras, ${ }^{5}$ como também se destacou pelos seus investimentos em território

3. Segundo Harvey (20I2), o neoliberalismo é uma teoria das práticas político-econômicas em que o bem-estar humano é promovido através das liberdades e capacidades empreendedoras individuais no âmbito de uma estrutura institucional caracterizada pelo direito à propriedade privada, livre mercado e livre comércio, cabendo ao Estado preservar uma estrutura institucional apropriada a essas práticas. Nesse sentido, o autor assinala que: “[...] o Estado tem de garantir, por exemplo, a qualidade e funçôes militares, de defesa, da polícia e legais requeridas para garantir direitos de propriedade individuais e para assegurar, se necessário pela força, o funcionamento apropriado dos mercados. Além disso, se não existem mercados (em áreas como a terra, a água, a instrução, o cuidado de saúde, a segurança social ou a poluição ambiental), estes devem se aventurar para além dessas tarefas. As intervençôes do Estado nos mercados (uma vez criados) devem ser mantidas num nível mínimo, porque, de acordo com a teoria, o Estado possivelmente não possui informaçóes suficientes para entender devidamente os sinais do mercado (preços) e porque poderosos grupos de interesse vão inevitavelmente distorcer e viciar as intervençóes do Estado (particularmente nas democracias) em seu próprio benefício" (Harvey, 20I2, p. I2).

4. UNCTAD. Disponível em: http://unctad.org/en/Pages/Home.aspx.

5. A participação da República Popular da China como destino das exportaçóes brasileiras saiu de $2 \%$, em 2000 , para 6,2\%, em 2003, alcançando I5,2\%, em 20I0, e saltando, para 19,2\%, em 2013, apresentando, entretanto, sensível recuo, para I8\%, em 20I4. Com efeito, essa República Popular mantém posição relevante como parceiro comercial do Brasil desde 20Io, inserindo o país entre os seus dez principais parceiros comerciais, haja vista que, entre 200I e 20I4, o Brasil apresentou uma trajetória ascensional entre os principais parceiros comerciais da República Popular da China, saindo da $\mathrm{II}^{\mathrm{a}}$ posição para a $8^{\mathrm{a}}$ posição, em 2013. 
nacional. Havendo assim, que se recordar do encontro entre os presidentes Xi Jinping e Dilma Rousseff, em julho de 20I4, quando mais de 50\% dos acordos assinados se concentraram nos setores comercial e de investimentos, bem como da recente visita ao país, do primeiro-ministro chinês Li Keqiang, em maio de 2015 - cuja ocasião resultou na assinatura de mais trinta atos e acordos bilaterais, atingindo, US $\$ 27$ bilhóes, ${ }^{6}$ destacando-se os setores de mineração, ciência e tecnologia, e energia (CEBC, 2015).

A fim de preencher algumas lacunas sobre a origem do influxo de IED no país, o artigo em tela póe seu foco sobre a presença do capital sínico 7 no território nacional, tendo como objetivo identificar o volume de investimentos chineses confirmados no Brasil entre 2007-20I6 e evidenciar a inserção do território fluminense nesse processo. A condução da problematização desse estudo decorre da confirmaçáo de investimentos chineses no estado do Rio de Janeiro, entre os anos 2010 e 2016.

Esse capital contribuiu para a implantação de atividades produtivas nos setores de energia, siderurgia, ferroviário, infraestrutura, informática e automotivo, em um território, que, conforme aponta Oliveira (2012), tem se caracterizado, desde a década de 1990 , pelas transformaçóes estruturais em sua base econômica e em suas redes técnicas de suporte à implantação de novas atividades produtivas, assim como pelo movimento de inversão da concentraçáo de recursos e investimentos. Nesse sentido, procuramos compreender quais os motivos e/ou fatores conduzem a inserção do estado do Rio de Janeiro como recipiendário de investimentos chineses?

A fim de atender a essas expectativas, alguns procedimentos metodológicos foram adotados para a realização deste estudo quali-quantitativo, compreendendo: i) o levantamento de referências sobre o tema em publicaçóes acadêmicas e periódicos especializados; ii) consultas ao sítio eletrônico da UNCTAD, para a realização do levantamento dos dados quantitativos sobre fluxos e estoques de IED no Brasil e sobre os fluxos e estoques de IED da República Popular da China no mundo; iii) a sistematização dos dados referentes aos investimentos chineses confirmados no Brasil, entre $2007 \mathrm{e}$ 20I6, e no estado do Rio de Janeiro, entre 2010 e 20I6, a partir das publicaçóes do Centro Empresarial Brasil China (CEBC); e iv) na busca pela com-

6. Disponível em: http://cebc.org.br/sites/default/files/declaracao_imprensa_-_pm_li_keqiang.pdf. Acesso em: 22 nov. 2015.

7. Capital de origem chinesa. 
preensão do processo de reestruturação do território fluminense, realizamos o levantamento da trajetória de crescimento do PIB estadual, entre os anos I990-20I4, bem como a participação de suas regiôes de governo na composição econômica do estado do Rio de Janeiro, entre 2000 e 2012, a partir de dados da Fundação CEPERJ.

A estruturação do capítulo ${ }^{8}$ em tela compreende três seções que sucedem esta introdução. Nas linhas correntes da primeira seção, evidenciamos o estado do Rio de Janeiro como nosso objeto de estudo e resgatamos a trajetória econômica fluminense a fim de elencar a perda da centralidade política (I960) e econômica no decorrer do século XX. Consideramos o prisma do esvaziamento econômico e das perdas relativas, especialmente, para tratar o período compreendido entre os anos de 1930 e 1980, para em seguida abordarmos a reestruturação do território fluminense, após a década de 1990, evidenciando tanto a trajetória de crescimento do PIB do estado, quanto a reorganização da participação das regiôes fluminenses na composição econômica estadual.

A segunda seção traz considerações sobre a passagem da República Popular da China da condição de recipiendária de investimentos externos a investidora internacional, identificando o volume de investimentos realizados pelo país asiático e a reorganização geográfica na distribuição dos seus investimentos no mundo nos últimos anos. A fim de identificar o volume desses no território nacional entre 2007-20I6, apresentamos ao final da seção o influxo dos mesmos no Brasil e o número de projetos originados pelo capital sínico no país. Em seguida, a terceira seção trata a inserção do território fluminense no processo de internacionalização dos investimentos chineses, analisando os investimentos chineses confirmados no estado do Rio de Janeiro entre os anos 2010 e 2016 , bem como a implantação de projetos de empresas chinesas que ocorreram nesse período. Sendo essa seção, sucedida pelas consideraçóes finais do capítulo.

8. É um produto resultante dos estudos desenvolvidos durante o mestrado no Programa de Pós-Graduaçâo em Geografia da UERJ, assim como da continuidade da pesquisa no doutoramento pelo Programa de Pós-Graduação em Geografia da PUC-Rio, ambos sob a orientaçấo do Prof. Dr. Glaucio J. Marafon. Há que se destacar aqui a contribuição da Prof. ${ }^{a}$ Danielle Figueredo Elias na traduçáo do resumo para língua inglesa e revisáo deste texto. 


\section{O território fluminense: trajetória econômica e o processo de reestruturaçáo}

\section{I A trajetória econômica fluminense (1930-1980): a dupla perda de centralidade}

$\mathrm{O}$ atual recorte espacial compreendido pelo território fluminense foi caracterizado, durante o século XX, por uma dupla perda de centralidade. ${ }^{9}$ Com a transferência do Distrito Federal para Brasília, em 1960, ocorre a perda da capitalidade e, por conseguinte, a perda da centralidade política do Rio de Janeiro.

Esse processo implicou a formação de duas unidades federativas (o estado da Guanabara e o estado do Rio de Janeiro), que quando fundidas, em Is de março de 1975, originaram a atual configuração territorial do estado. Em decorrência desse processo, uma nova centralidade política foi implantada na região Centro-Oeste, por meio da instalação de Brasília, no Planalto Central, como metrópole política do país (Santos e Silveira, 2008).

A perda da centralidade econômica fluminense, entretanto, é decorrente de um processo longo, abrangendo algumas décadas do século XX. Assim aquela centralidade exercida pelo espaço fluminense que, até o início daquele século, esteve atrelada à proeminência econômica, processualmente obtida nos períodos colonial, imperial e republicano do Brasil, dado o acúmulo de funçôes (comercial, portuária, militar, industrial e da administração pública), foi perdida com o intenso desenvolvimento industrial no estado de São Paulo e a afirmação da cidade de São Paulo como a metrópole econômica do país (Santos e Silveira, 2008).

Acerca do processo de perda de centralidade econômica fluminense, os trabalhos de Melo (200I) e Silva (20I2) elencam o período de I930-I980, respectivamente, sob o prisma do esvaziamento econômico e das perdas relativas, denotando uma conjuntura econômica involutiva que, além de abarcar a perda de centralidade mencionada, evidencia, respectivamente, tanto o processo de perda de participação fluminense na produção industrial do país quanto a redução do Rio de Janeiro no PIB nacional.

\footnotetext{
9. Por questôes metodológicas que auxiliam na compreensão da atual configuração do estado do Rio de Janeiro, optamos em tratar, inicialmente, a perda da centralidade política da cidade do Rio de Janeiro decorrente da transferência do Distrito Federal para Brasília.
} 
Melo (200I) e Araújo e Melo (20I4) evidenciam que, entre os anos de 1930 e 1980, o estado do Rio de Janeiro assistiu a um esvaziamento econômico em decorrência da trajetória de diminuição de sua participação em percentuais na produção industrial brasileira. Todavia, os autores apontam que, apesar de ser o berço da industrialização do país, a indústria fluminense assistiu, desde a década de 1930, a um inexorável processo de esvaziamento, perdendo posição para a indústria paulista.

Como resultado, naquela década, a participação do Rio de Janeiro somada com a do Distrito Federal correspondia a menos da metade da participação do estado de São Paulo na produção industrial do país, sendo mantida a trajetória de redução da participação fluminense na produção industrial nacional ao longo de praticamente toda segunda metade do século XX. Portanto, se, por um lado, a participação fluminense na produção industrial, entre 1907 e 2000, apresentou retração de aproximadamente $31 \%$, dada a queda de $40 \%$, em 1907 , para 8,6\%, em 2000, por outro lado, o estado de Sáo Paulo apresentou uma trajetória ascendente, destacadamente, entre 1907 e 1975, com uma participação na produção industrial nacional que saltou de $16,5 \%$, naquele ano, para quase 60\%, em meados da década de 1970 (gráfico I).

Gráfico I - Rio de Janeiro e São Paulo: participação na produção industrial do Brasil entre 1907-2000 ${ }^{\text {Io }}$

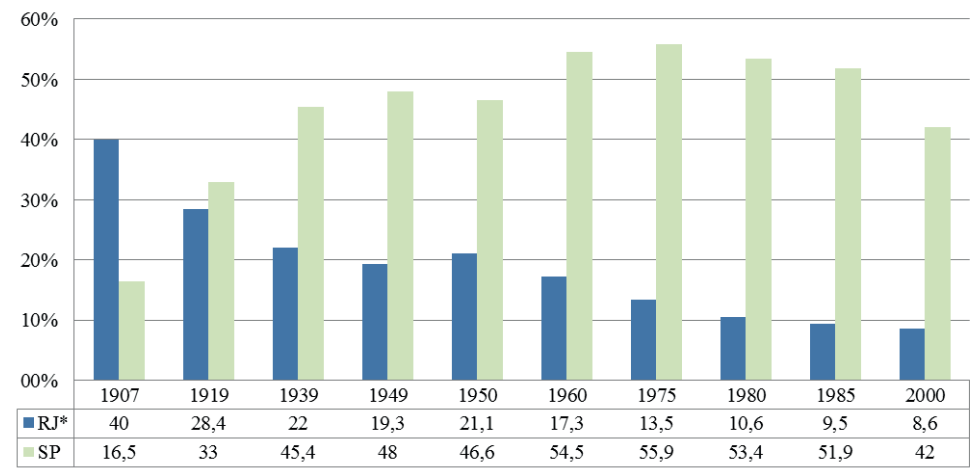

Fonte: Melo, 200I e Araújo e Melo, 20I4 - gráfico elaborado pelo autor.

Segundo Silva (20I2, p. 4I), a trajetória que "passou a ser comumente interpretada como um processo de 'esvaziamento' e 'decadência' econômica re-

Io. Soma da cidade do Rio de Janeiro com o estado do Rio de Janeiro entre I907 e 1975. 
gional" foi compreendida como combinação da acelerada expansão industrial em território nacional e perdas reais de alguns ramos da economia estadual, de modo que, na compreensão do autor, "se fosse possível sintetizar, em uma frase, o desenvolvimento capitalista fluminense entre 1930-1980, a que melhor sintetizaria esse processo seria, muito possivelmente, crescimento e modernização com perda de importância relativa” (Silva, 20I2, p. 4I). Todavia, o autor assinala que "o Rio de Janeiro, como espaço pioneiro de vários setores, não conseguiu acompanhar o crescimento relativo dos novos espaços, perdendo participação relativa no total nacional” (p. 52).

Nessa perspectiva, compreende-se que a economia fluminense foi marcada por uma trajetória de redução de sua participação no PIB nacional, tendo um perfil relativo, ou seja, resultou do descompasso entre suas taxas e a média do país. Como implicação desse processo assiste-se, atualmente, a contínua redução da participação do estado do Rio de Janeiro no PIB nacional, especialmente, quando se nota que no decorrer do século XX, a participação declinou de $21 \%$, em I939, para II\%, em I995, ocorrendo uma sensível melhora da participação, na passagem para o século XXI, quando no decênio 1995-2005, esta subiu para, aproximadamente, I2\%. Entretanto, voltando a retrair para, aproximadamente, II\%, entre 2006 e 2014 (gráfico 2).

Gráfico 2 - Participação do estado do Rio de Janeiro no PIB nacional entre I939-20I4

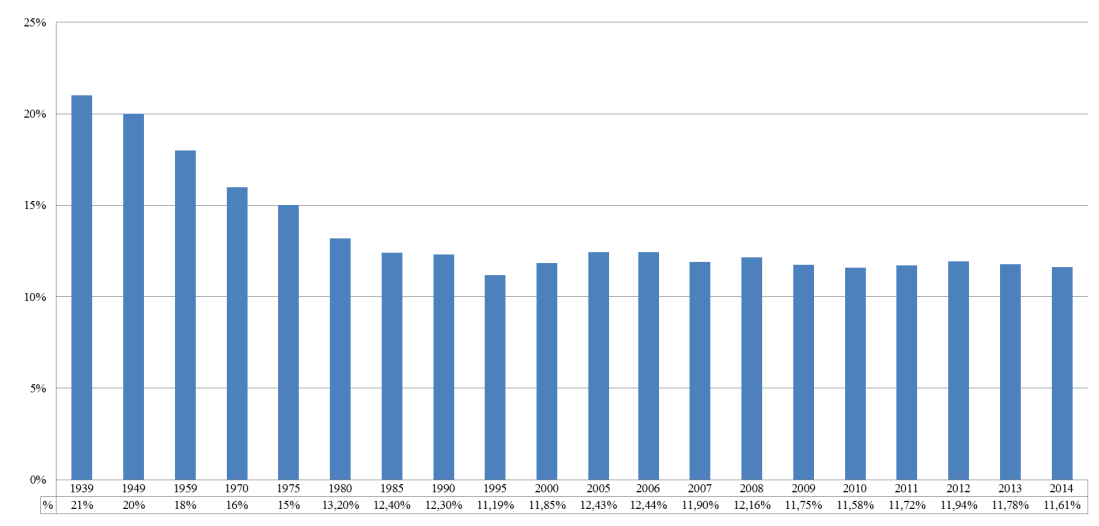

Fonte: Santos, 2003; Silva, 20I2; CEPERJ, s. d. ${ }^{\text {II }}$ - gráfico elaborado pelo autor.

II. Disponível em: http://www.ceperj.rj.gov.br/ceep/pib/pib.html. Acesso em: o7 ago. 2017. 
A partir dessas considerações, pode-se compreender que a trajetória econômica fluminense ao longo do século XX, destacadamente entre 1930-1980, foi marcada pela perda de centralidade econômica, em decorrência tanto da redução de sua participação na produção industrial nacional quanto pela retração da contribuição fluminense no PIB nacional, implicando o ingresso do território fluminense em uma trajetória que foi denominada de "esvaziamento econômico", e que mais recentemente foi compreendida enquanto "perdas relativas" de participaçáo fluminense na economia nacional (Melo, 20or; Silva, 20I2; Araújo e Melo, 20I4).

No entanto, ainda que marcado por uma conjuntura econômica involutiva, decorrente do negativo desempenho da economia nacional nos anos I980, o estado do Rio de Janeiro teve que aguardar a década de 1990 para assistir um conjunto de mudanças atreladas à implantação de novas atividades produtivas, a realização de novos investimentos em infraestrutura e as alteraçôes nas bases de suas economias regionais, o que desencadearia seu processo de reestruturação. Essas mudanças são discutidas nas linhas subsequentes quando se volta atenção à compreensão sobre o processo de reestruturação do território fluminense e a inserção dos investimentos chineses no estado no início do século XXI.

\subsection{A trajetória econômica fluminense (pós-1990): o processo de reestruturaçáo e o influxo de investimentos chineses}

A atual configuração territorial do estado do Rio de Janeiro (figura I), com extensão de 43,7 mil km², permite que essa unidade federativa (UF) estabeleça divisas com outros três estados da regiáo Sudeste do Brasil, apresentando uma organização político-administrativa, hodiernamente, formada por oito regióes de governo e malha municipal constituída por 92 municípios. O estado do Rio do Janeiro não está apenas próximo do Espírito Santo, Minas Gerais e São Paulo, sendo juntamente com estes responsável por, aproximadamente, 55\% do PIB nacional. 
Figura I - Estado do Rio de Janeiro: a RMRJ e o interior fluminense

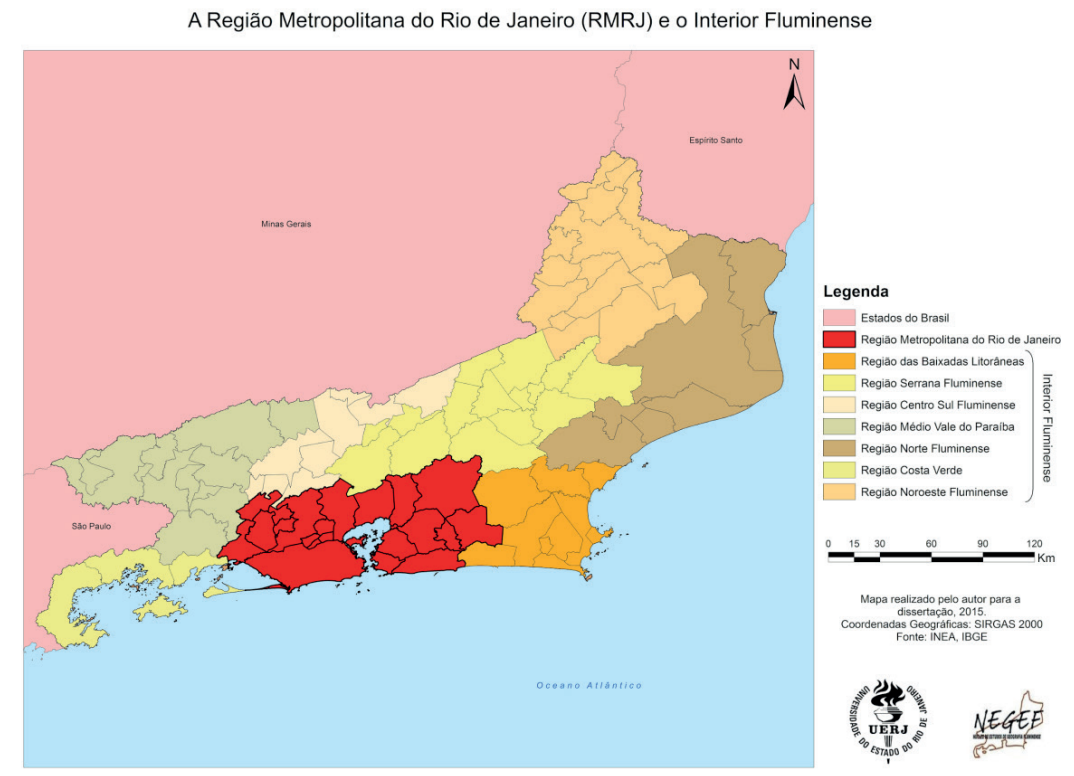

Fonte: $\mathrm{O}$ autor, 2015 .

Tamanha concentração na composição do PIB do país evidencia tanto a característica assimétrica do desenvolvimento capitalista brasileiro (Silva, 20I2) quanto justifica a manutenção de uma agenda de pesquisa acerca do território fluminense, sobretudo, pela sua importância no âmbito econômico e produtivo nacional. Segundo Oliveira ${ }^{12}$ (2OI2, p. I3I), "o território fluminense necessita ser estudado em sua totalidade, como espaço social que passa por um conjunto de mudanças nas condiçóes gerais de produçáao", destacadamente, porque:

a organização do território fluminense como um todo passou nas últimas duas décadas por transformaçôes estruturais em sua base econômica e nas redes técnicas de suporte às novas atividades produtivas, iniciando um movimento de inversão da concentração de recursos, população e investimentos que caracterizaram as duas cidades do núcleo metropolitano, ou seja, Rio de Janeiro e Niterói.

I2. Com base em Lencioni (2007). 
Essas novas atividades, a princípio, foram resultantes de ações empresariais que atuam no mercado internacional, cujas decisóes ocorrem nos principais centros econômicos do capitalismo contemporâneo. A partir desses centros é que são decididos os usos dos territórios, apropriando-se dos recursos existentes em cada lugar por setores econômicos globalizados, cujos objetivos são pura e simplesmente a exploração dos recursos locais e a acumulação de capitais (Oliveira, 20I2, p. I32).

Convergimos com Oliveira (2012) quando o autor aponta que o estado do Rio de Janeiro, enquanto "um território em mudanças", tem suas principais transformaçôes territoriais relacionadas aos processos de transformaçóes das bases econômicas, iniciados nos primeiros anos da década de I990, destacadamente, quando assinala que:

as mudanças nas bases técnicas no interior do estado, sobretudo, no Norte Fluminense, cujas bases econômicas eram atividades agroindustriais sucroalcooleiras e, hoje, predominam a indústria do petróleo e gás, por meio das atividades extrativistas e logísticas. No outro extremo, no sul do estado, onde havia uma base isolada do setor siderúrgico, liderada pela Companhia Siderúrgica Nacional (CSN), instala-se um complexo polo metal-mecânico e siderúrgico, ampliado pelas indústrias automobilísticas e pelas atividades portuárias da região (Oliveira, 20I2, pp. I32-3).

Essas mudanças, segundo o autor supracitado, só ganham visibilidade quando atingem o espaço metropolitano, influindo na reversão do quadro de estagnação que perdurou até a década de 1980 e início dos anos 1990. Especialmente com a instalação de novos fixos nessa porção do território e o (re)acionamento de setores produtivos localizados na Região Metropolitana do Rio de Janeiro (RMRJ), que se encontravam estagnados como, por exemplo, a indústria naval.

Na perspectiva de Silva (2OI2), essas mudanças contribuíram para que o território fluminense chegasse ao século XXI internamente constituído por um parque industrial dotado de novas plantas industriais, porém pouco articulado, dado o estabelecimento de dois padrốes de especialização: o da produção petrolífera do Norte Fluminense e o da produção manufatureira no Sul Fluminense. Cabendo a RMRJ, apesar de sua densidade econômica e demográfica, assistir um padrão de desenvolvimento assentado na terciarização e na desindustrialização, bem como um processo de mudança na sua contribuição percentual na economia fluminense. 
Diante do exposto acerca das mudanças que ocorreram no território fluminense, após a década de 1990 , consideramos sua reestruturação sob o prisma econômico-produtivo. Considerando, assim, a trajetória de influxo de investimentos no território fluminense e o crescimento econômico do estado do Rio de Janeiro, acompanhado da reorganização da participação de suas economias regionais na composição do PIB estadual.

A noção de reestruturação que nos orienta pode ser compreendida, conforme assinala Soja (1993), enquanto um processo resultante da modificação da estrutura de um espaço material, de maneira rápida ou lenta, ocorrendo em diferentes escalas, nas quais fatores econômicos, políticos e ideológicos frequentemente combinados transmitem a noção de ruptura nas tendências seculares. Sendo essa noção também apreendida como um processo de mudança estrutural expressivo em direção a uma ordem e a uma configuração significativamente diferente na vida social, econômica e política (Santos, 2008; Sou$\mathrm{za}, 2 \mathrm{OI})$.

No caso do território fluminense, a superação da trajetória de estagnação ocorre pari passum ao processo de retomada de crescimento econômico do estado, apesar de náo ter sido capaz de reverter a sua perda de importância na economia nacional - sendo esta mantida em, aproximadamente, II\% -, ela se caracterizou por uma nova conjuntura econômico-produtiva. As principais características dessa nova conjuntura econômico-produtiva se constituem tanto pela trajetória de influxos de investimentos e implantação de novas atividades produtivas no território quanto pelo crescimento do seu PIB e reorganização dos percentuais de participação de suas economias regionais na economia do estado.

No que concerne ao crescimento econômico e a reorganização da participação das economias regionais, torna-se possível dimensionar a conjuntura de mudanças, quando o PIB fluminense saltou de $\mathrm{R} \$ 78,9$ milhóes, em I995, para R\$ 67I,o milhôes, em 20I4; ampliando, de modo pouco significativo, seu percentual de participação na economia nacional entre 1995 e 20I4, mantendo-se esta participação nesse período entre II\% e I $2 \%$, ou seja, pouco superior à contribuição apresentada na metade dos anos 1990 (gráfico 3).

Além da conjuntura de mudanças pela qual passou o território fluminense poder ser evidenciada com o crescimento do PIB do estado do Rio de Janeiro, a partir da década de 1990, torna-se possível dimensionar esse processo com a reorganização das taxas de participação econômico-regional, em um pe- 
ríodo mais recente, destacadamente entre os anos 2000 e 20I4. Portanto, nota-se que nesse período o crescimento do PIB estadual saiu de $\mathrm{R}$ \$ 139,7 milhóes, em 2000, para $\mathrm{R} \$ 671$, o milhóes, em 20I4; ocorrendo o aumento da participação da porção interiorana do estado na economia fluminense.

Como resultado, o interior fluminense elevou sua participação no PIB estadual, em II,O\%, no referido período, passando sua contribuição no PIB estadual de $26 \%$, em 2000 , para $37 \%$ em 2014 . No entanto, a Regiáo Metropolitana do Rio de Janeiro assistiu tanto aos processos de desindustrialização e terciarização, assinalados por Silva (2012), quanto à diminuição de sua participação de $74 \%$, em 2000, para 63\%, em 2014 (tabela I), o que evidencia o processo de inversão da concentração econômico-produtiva e de recursos no território fluminense.

Gráfico 3 - Estado do Rio de Janeiro: PIB e participação no PIB nacional entre I995 e 2014

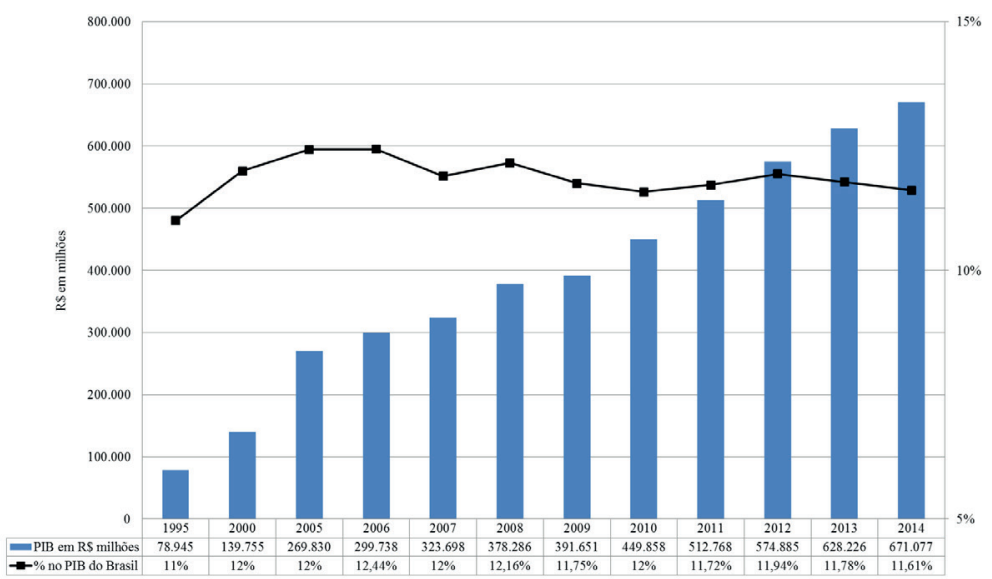

Fonte: Fundação CEPERJ ${ }^{13}$ - gráfico elaborado pelo autor.

Tabela I - Estado do Rio de Janeiro: PIB por regióes de governo (\%) (2000-20I4)

\begin{tabular}{llll} 
Regióes de governo & $\mathbf{2 0 0 0}(\mathbf{\%})$ & $\mathbf{2 0 1 4} \mathbf{( \% )}$ & Variação \% \\
\hline Metropolitana & $74 \%$ & $63 \%$ & $-\mathrm{II} \%$ \\
\hline Interior Fluminense & $26 \%$ & $37 \%$ & $\mathrm{II} \%$ \\
\hline Norte Fluminense & $7 \%$ & $\mathrm{I} 6 \%$ & $9 \%$ \\
\hline Médio Paraíba & $7 \%$ & $5 \%$ & $-2 \%$ \\
\hline
\end{tabular}

I3. Disponível em: http://www.ceperj.rj.gov.br/ceep/pib/pib.html. Acesso em: 20 jul. 2017. 


\begin{tabular}{llll} 
Regióes de governo & $\mathbf{2 0 0 0} \mathbf{( \% )}$ & $\mathbf{2 0 I 4} \mathbf{( \% )}$ & Variação \% \\
\hline Serrana & $4 \%$ & $4 \%$ & $\mathrm{O} \%$ \\
\hline Baixadas Litorâneas & $4 \%$ & $8 \%$ & $4 \%$ \\
\hline Centro-Sul Fluminense & $\mathrm{I} \%$ & $\mathrm{I} \%$ & $\mathrm{O} \%$ \\
\hline Noroeste Fluminense & $\mathrm{I} \%$ & $\mathrm{I} \%$ & $\mathrm{O} \%$ \\
\hline Costa Verde & $\mathrm{I} \%$ & $2 \%$ & $\mathrm{I} \%$ \\
\hline
\end{tabular}

Fonte: FUNDAÇÃO CEPERJ ${ }^{\mathrm{I4}}$ - tabela elaborada pelo autor como base na participação por atividade econômica e no valor adicionado bruto, segundo as regióes de governo e municípios - 2000/2014.

Todavia, como bem assinalam Terra et al. (20I2), em meio a essa conjuntura de mudanças, o supracitado estado se destacou na carteira de investimentos industriais, logísticos e de serviços. No que concerne aos investimentos chineses confirmados no país, o estado do Rio de Janeiro recebeu grande aporte desse capital. Com efeito, entre 2010 e 20I6, o influxo de investimentos chineses no território fluminense compreendeu, aproximadamente, US $\$ 2$ I,9 bilhôes, abrangendo assim grande parte dos investimentos chineses confirmados no Brasil, entre 2007 e 2016 , quando a soma desse capital compreendeu, aproximadamente, US\$46, I bilhôes (CEBC, 2017) (gráfico 4).

Gráfico 4 - Investimentos chineses confirmados no estado do Rio de Janeiro

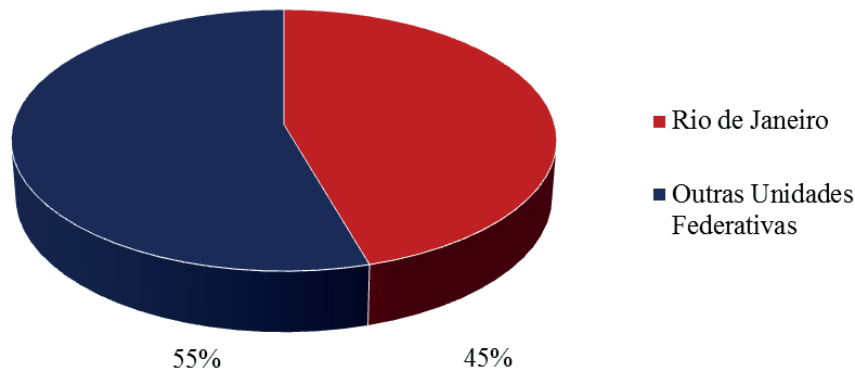

US $\$ 21,9$ bilhões

US\$ 24,2 bilhões

Fonte: CEBC, 2017 - gráfico elaborado pelo autor.

I4. Disponível em: http://www.ceperj.rj.gov.br/ceep/pib/pib.html. Acesso em: 20 jul. 2017. 


\section{A reorganizaçáo geográfica dos investimentos chineses no mundo e a inserção do Brasil no processo de internacionalização dos IED chineses}

No final dos anos 1970, a República Popular da China ${ }^{\text {Is }}$ assistiu à abertura econômica aos investimentos estrangeiros e as reformas realizadas pelo governo Deng Xiaoping (1978-1992). Como resultado, o país asiático ascendeu, ao longo de seu processo de desenvolvimento econômico, de recipiendário de investimentos estrangeiros à condição de investidor internacional.

O influxo de investimentos externos na República Popular da China se manteve crescente, ao longo do último quarto de décadas do século XX e do início do século XXI, ocorrendo um salto de, aproximadamente, US\$57 milhões, em 1980, para US \$ I,9 bilhão, em 1985, assim como considerável trajetória de ampliação dos US\$37,5 bilhôes, em I995, ao atingir US \$ 135,6 bilhões, em 2015 (gráfico 5). Sendo possível notar que o período de maior influxo de investimentos no território chinês compreende o recorte temporal entre os anos 1990 e as primeiras décadas do século corrente.

No que concerne à internacionalização dos investimentos chineses, pode-se compreender que, embora as primeiras concessóes para efetuar investimentos no exterior remontem a passagem entre os anos I979-I980, foi somente a partir da década de I990, que aquele país ampliou sua participaçáo no fluxo e no estoque de IED no mundo (Buckley et al., 20ıо; Oliveira, A., 20I2; CEBC, 20I3; Alves, 2014). Como resultado, a República Popular da China atingiu US\$ 127,5 bilhões em fluxos de investimentos no exterior, em 20I5, alcançando US \$ I, o trilhão, em seus estoques de IED no mesmo ano (gráfico 6).

I5. Com uma projeção histórico-econômica muito densa, reconhecemos, conforme assinala Kissinger (2OII, p. 2I), que "qualquer tentativa de compreender [...] o papel mundial da China no século XXI deve começar - mesmo ao preço de uma possível simplificação excessiva - por uma apreciação básica do contexto tradicional”. Nesse sentido, sinalizamos que este país localizado na Ásia Oriental, tem um contexto tradicional que remonta o período de Estados Combatentes e à unificação territorial em 22I a.C, que conformou o Império Chinês. Nessa seção, abordaremos a China que, após se reunificar no início do século XX - com a instauração da República (I9I2) -, passou por um processo revolucionário em I949, que tirou o país asiático do século da humilhação e o conduziu à atual República Popular da China. 
Gráfico 5 - República Popular da China: influxo de IED - 1980-20I5

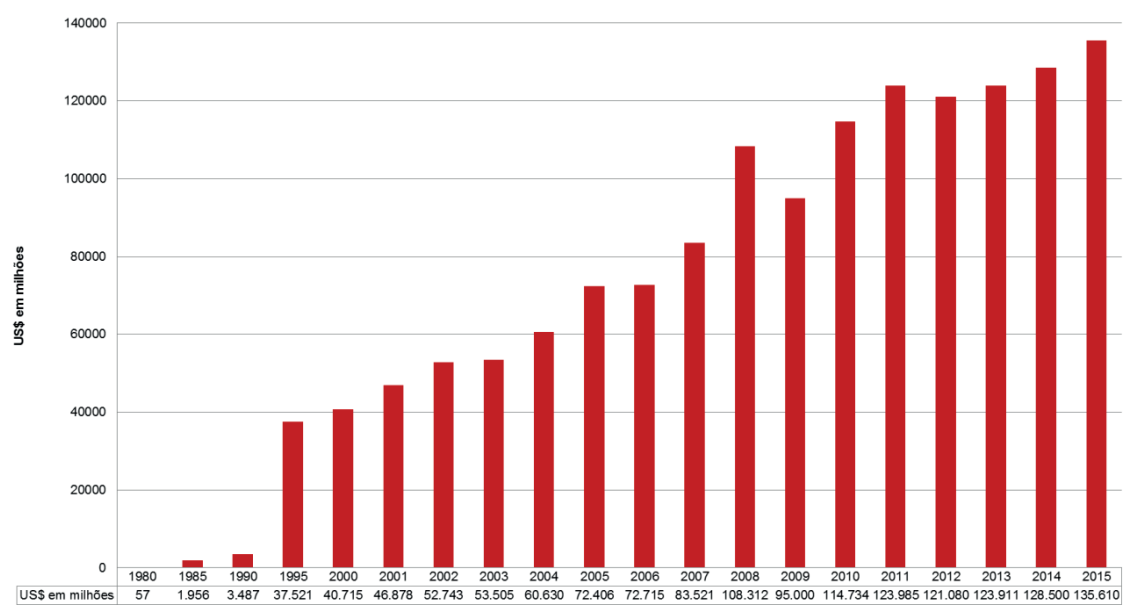

Fonte: UNCTAD ${ }^{16}$ - gráfico elaborado pelo autor.

Gráfico 6 - República Popular da China: fluxo e estoque de IED no exterior - I980-2015

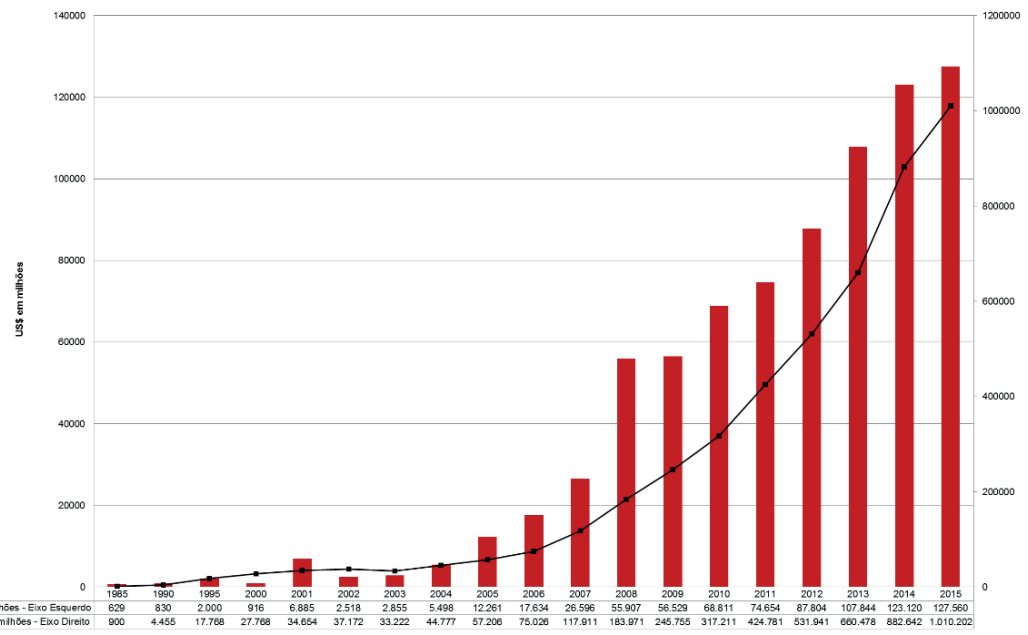

Fonte: UNCTAD ${ }^{17}$ - gráfico elaborado pelo autor.

I6. Disponível em: http://unctadstat.unctad.org/wds/TableViewer/tableView.aspx. Acesso em: Io jun. 2017.

I7. Disponível em: http://unctadstat.unctad.org/wds/TableViewer/tableView.aspx. Acesso em: Io jun. 2017. 
O desempenho alcançado como investidor internacional pela República Popular da China remonta a uma trajetória gradual de expansão de seus investimentos no exterior, ${ }^{18}$ dotando-a de capacidades político-econômicas de investir em diferentes regióes do mundo com assertividade e pragmatismo. Com efeito, o país asiático expandiu a atuação de suas empresas estatais e investiu em diferentes regióes do espaço mundial.

A República Popular da China manteve, inicialmente, a maior parte dos seus investimentos externos em países desenvolvidos, entretanto, mais recentemente, a reorganização geográfica na distribuição espacial de seus investimentos no exterior conduziu os países em desenvolvimento à condição de maiores receptores de IED chineses (IPEA, 20II). Assim, os fluxos e estoques de IED chineses, em 20I2, se concentravam na Ásia e na América Latina e Caribe, sendo essas regióes seguidas, no que concerne aos fluxos, pela Europa, América do Norte, economias em transição, outros países desenvolvidos e África. No que tange aos estoques, Ásia e América Latina e Caribe são sucedidas pela Europa, América do Norte, outros países desenvolvidos, África e economias em transição (gráfico 7) . ${ }^{19}$

Gráfico 7 - República Popular da China (RPC): fluxos e estoques de IED no exterior, por regiôes em 2012

A) RPC: fluxos de IED por regiōes em 2012

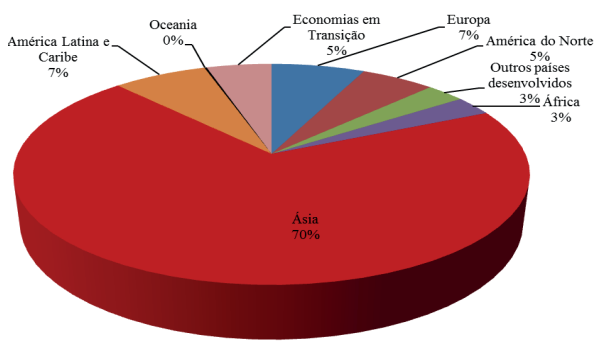

Fonte: $\mathrm{UNCTAD}^{20}$ - gráfico elaborado pelo autor.
B) estoques de IED por regiōes em 2012

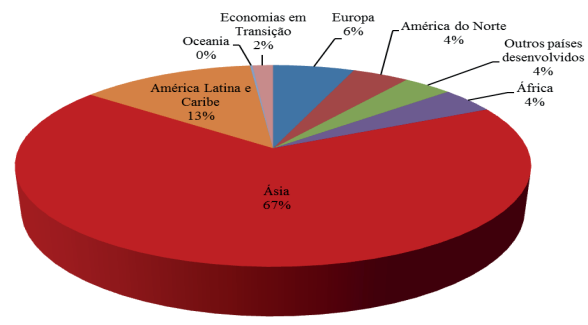

I8. Acerca desse processo, ver Buckley et al. (20I0), Oliveira, A. (2012), CEBC (2013) e Alves (2014).

19. Terminologias da UNCTAD.

20. Disponível em: http://unctad.org/Sections/dite_fdistat/docs/webdiaeiazor4d3_CHN.pdf. Acesso em: 20 jul. 2017 . 
No que concerne às relaçóes sino-brasileiras, conforme assinalado, a República Popular da China, além de principal parceiro comercial do Brasil, vem se destacando no relacionamento bilateral com este país sul-americano, como um novo investidor internacional. Com efeito, durante o período compreendido entre os anos de 2007 e 20I6, é possível identificar que US\$ 46, I bilhóes em IED chineses foram confirmados no território nacional (gráfico 8).

Diante do exposto, percebe-se que, embora presente entre 2007 e 2009, o influxo de investimentos chineses confirmados no país foi baixo, compreendendo, quando somados, US\$549 milhóes. Entretanto, a partir de 20IO, o ingresso desses investimentos foi consideravelmente ampliado no território nacional, dada a confirmação de US $\$$ I3, o bilhóes, sendo sucedido, nos anos subsequentes, por novos investimentos, apesar de menores em relação ao ano de 2010 , como: US $\$ 8$, o bilhôes, em 20II; US $\$ 3,4$ bilhões, em 20I2; US\$3,4 bilhôes, em 20I3; US\$ I,7 bilhões, em 20I4; US\$ 7,4 bilhôes, em 2015; e US $\$ 8,3$ bilhóes, em 2016 - compreendem volumes de investimentos confirmados que não se mostraram inferiores ao período de 2007-2009.

Gráfico 8 - Investimentos externos diretos chineses confirmados no Brasil - 2007-2016

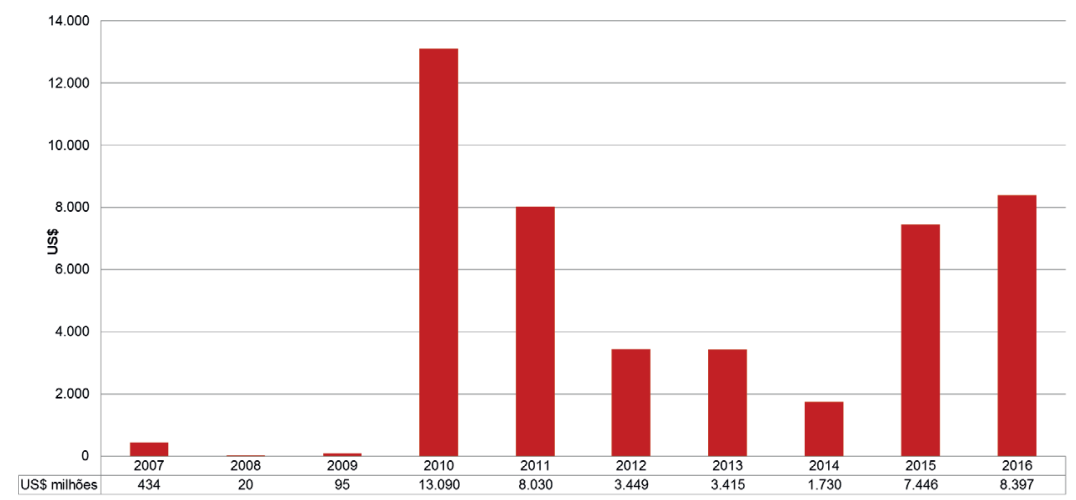

Fonte: CEBC, 2017 - gráfico elaborado pelo autor.

Portanto, se, por um lado, entre 2010 e 20I4, houve redução do aporte de investimentos chineses no Brasil, por outro, entre 2014 e 20I6, houve a retomada desses investimentos no país. O volume de capital chinês investido no país ao longo dos anos de 2007 a 2016 equivaleu à confirmação de 88 projetos (gráfico 9). 
Gráfico 9 - Projetos de investimentos chineses confirmados no Brasil - 2007-2016.

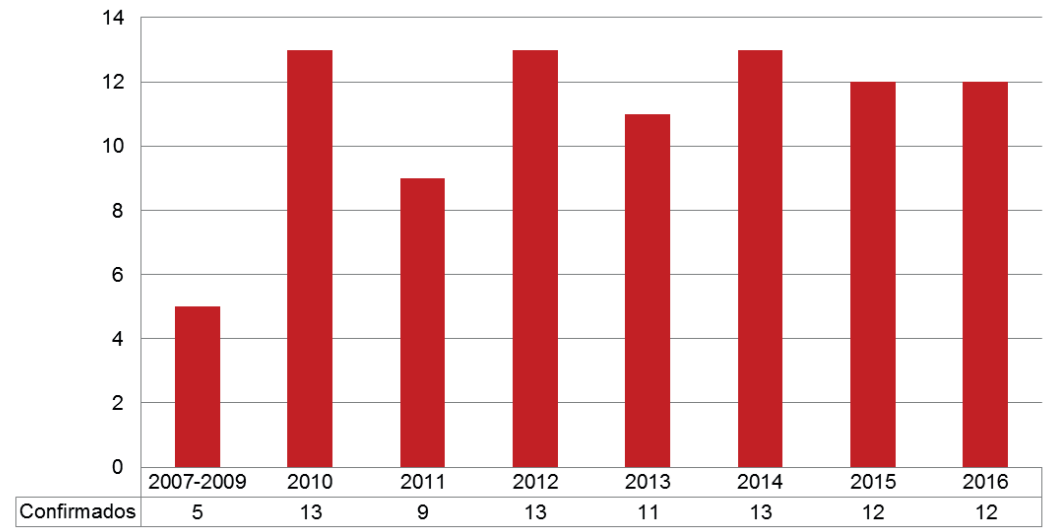

Fonte: CEBC, 2016 - gráfico elaborado pelo autor.

O número de projetos e o volume de capitais investidos nos setores de energia e agronegócio foram representativos. No entanto, outros setores, como o de siderurgia, máquinas e equipamentos, automobilístico, aviação, financeiro e, mais recentemente, os de informática e de infraestrutura, têm diversificado as atividades receptoras de investimentos chineses no Brasil (CEBC, 20I5, 2016, 2017).

Nota-se, no caso brasileiro, que como desdobramento da influência da teoria neoliberal na reforma administrativa do país, ocorre tanto um processo de reestruturação do estado por meio da abertura econômica, das privatizaçôes e da redução do intervencionismo quanto à participação mais recente do capital sínico no processo de "desnacionalização profunda", apontado por Miranda e Tavares (1999), e de "transnacionalização do território", assinalado por Santos (20I2). Diante desses processos, cabe-nos na próxima seção, evidenciar a inserçáo do estado do Rio de Janeiro como recipiendário desse influxo de investimentos chineses no país.

\section{A inserção do estado do Rio de Janeiro no processo de internacionalizaçáo dos investimentos chineses}

Apesar de apresentarem contribuiçôes acerca da retomada do crescimento econômico do estado do Rio de Janeiro, evidenciarem a reestruturação produtiva 
do território nas últimas duas décadas e avaliarem a trajetória econômica fluminense ao longo da passagem do século XX para o XXI, os estudos elencados neste capítulo não enfatizam o influxo dos investimentos chineses no território fluminense.

No sentido de preencher essa lacuna, identificamos, a partir das publicaçóes do CEBC, que, no período compreendido entre os anos de 2007 e 20I6, os investimentos chineses confirmados no Brasil compreenderam, aproximadamente, US $\$ 46$, I bilhôes. No território nacional, a região Sudeste se destaca como o centro de gravidade dos investimentos chineses, concentrando grande parte dos empreendimentos realizados no país (CEBC, 20I7).

Entre as unidades federativas, não somente na escala regional, mas também na escala nacional, os estados de São Paulo e do Rio de Janeiro se destacam como recipiendários desses investimentos. Este último, entre 2010 e 20I6, foi inserido no processo de internacionalização dos investimentos chineses, dado o influxo de aproximadamente US \$2I,9 bilhóes. Esse volume de capital representou, aproximadamente, $45,5 \%$, do montante dos investimentos chineses confirmados no país, correspondendo, assim, à implantação de dez projetos no território fluminense.

Os projetos que materializam os investimentos chineses no território fluminense abrangem os setores de energia, siderurgia, infraestrutura, ferroviário, de informática e automotivo (tabela 2). Sendo possível notar uma trajetória de continuidade dos investimentos chineses no estado, apesar da exceçáo nos anos 2012 e 20I4, a década corrente tem sido marcada pela entrada de IED chineses neste.

Tabela 2 - Investimentos chineses confirmados no território fluminense: 20I0-20I6

\begin{tabular}{|c|c|c|c|c|c|c|c|}
\hline Projeto & Ano & $\begin{array}{l}\text { Empresa } \\
\text { de origem }\end{array}$ & Valor em US\$ & $\begin{array}{l}\text { Modo de } \\
\text { entrada }\end{array}$ & Setor & $\begin{array}{l}\text { Estrutu- } \\
\text { ra de pro- } \\
\text { priedade }\end{array}$ & $\begin{array}{l}\text { Determi- } \\
\text { nante do in- } \\
\text { vestimento }\end{array}$ \\
\hline I & 2010 & $\begin{array}{l}\text { Sinopec } \\
\text { Repsol } \\
\text { Brasil* }\end{array}$ & 7.109.000.000 & $\begin{array}{l}\text { Fusóes e } \\
\text { aquisiçóes } \\
\text { (parcial) }\end{array}$ & $\begin{array}{l}\text { Energia (pe- } \\
\text { tróleo e gás) }\end{array}$ & $\begin{array}{l}\text { Central } \\
\text { SOE }\end{array}$ & $\begin{array}{l}\text { Busca de re- } \\
\text { cursos }\end{array}$ \\
\hline 2 & 2010 & $\begin{array}{l}\text { Sinochem } \\
\text { Statoil } \\
\text { ASA** }^{*}\end{array}$ & 3.070 .000 .000 & $\begin{array}{l}\text { Fusões e } \\
\text { aquisiçóes } \\
\text { (parcial) }\end{array}$ & $\begin{array}{l}\text { Energia (pe- } \\
\text { tróleo e gás) }\end{array}$ & $\begin{array}{l}\text { Central } \\
\text { SOE }\end{array}$ & $\begin{array}{l}\text { Busca de re- } \\
\text { cursos }\end{array}$ \\
\hline
\end{tabular}




\begin{tabular}{|c|c|c|c|c|c|c|c|}
\hline Projeto & Ano & $\begin{array}{l}\text { Empresa } \\
\text { de origem }\end{array}$ & Valor em US\$ & $\begin{array}{l}\text { Modo de } \\
\text { entrada }\end{array}$ & Setor & $\begin{array}{l}\text { Estrutu- } \\
\text { ra de pro- } \\
\text { priedade }\end{array}$ & $\begin{array}{l}\text { Determi- } \\
\text { nante do in- } \\
\text { vestimento }\end{array}$ \\
\hline 3 & 2010 & $\begin{array}{l}\text { CR Zong- } \\
\text {-shen*** }\end{array}$ & 20.000 .000 & Greenfield & Automotivo & Privada & $\begin{array}{l}\text { Busca de } \\
\text { mercado }\end{array}$ \\
\hline 4 & 2010 & $\begin{array}{l}\text { Wuhan } \\
\text { Iron/Stell } \\
\text { Group Co. } \\
\text { (Wisco) } \\
* * * *\end{array}$ & 3.500 .000 .000 & $\begin{array}{l}\text { Joint Ven- } \\
\text { ture }\end{array}$ & Siderurgia & $\begin{array}{l}\text { Central } \\
\text { SOE }\end{array}$ & $\begin{array}{l}\text { Busca de re- } \\
\text { cursos }\end{array}$ \\
\hline 5 & $2 \mathrm{OII}$ & $\begin{array}{l}\text { China } \\
\text { Northern } \\
\text { Railway } \\
* * * * *\end{array}$ & 200.000 .000 & $\begin{array}{l}\text { Fusóes e } \\
\text { aquisiçôes } \\
\text { (completa) }\end{array}$ & Ferroviário & SOE & $\begin{array}{l}\text { Busca de } \\
\text { mercado }\end{array}$ \\
\hline 6 & $2 \mathrm{OII}$ & $\begin{array}{l}\text { Sinopec } \\
* * * * * *\end{array}$ & 3.500 .000 .000 & $\begin{array}{l}\text { Fusóes e } \\
\text { aquisiçôes } \\
\text { (parcial) }\end{array}$ & $\begin{array}{l}\text { Energia (Pe- } \\
\text { tróleo e Gás) }\end{array}$ & $\begin{array}{l}\text { Central } \\
\text { SOE }\end{array}$ & $\begin{array}{l}\text { Busca de re- } \\
\text { cursos }\end{array}$ \\
\hline 7 & 2013 & $\begin{array}{l}\mathrm{CNPC} \mathrm{e} \\
\mathrm{CNOOC} \\
* * * * * * *\end{array}$ & I.500.000.000 & $\begin{array}{l}\text { Fusões e } \\
\text { aquisiçốes } \\
\text { (parcial) }\end{array}$ & $\begin{array}{l}\text { Energia (pe- } \\
\text { tróleo e gás) }\end{array}$ & $\begin{array}{l}\text { Central } \\
\text { SOE }\end{array}$ & $\begin{array}{l}\text { Busca de re- } \\
\text { cursos }\end{array}$ \\
\hline 8 & 2015 & Qihoo & 21.000.000 & $\begin{array}{l}\text { Fusões e } \\
\text { aquisiçóes }\end{array}$ & Informática & Privada & $\begin{array}{l}\text { Busca de } \\
\text { Mercado }\end{array}$ \\
\hline 9 & 2015 & $\begin{array}{l}\text { State Grid } \\
* * * * * * * *\end{array}$ & 2.905 .808 .000 & $\begin{array}{l}\text { Fusões e } \\
\text { aquisiçóes } \\
\text { (parcial) }\end{array}$ & Energia & $\begin{array}{l}\text { Central } \\
\text { SOE }\end{array}$ & $\begin{array}{l}\text { Busca de } \\
\text { mercado }\end{array}$ \\
\hline IO & 2016 & $\begin{array}{l}\text { China } \\
\text { Commu- } \\
\text { nications } \\
\text { Construc- } \\
\text { tion Com- } \\
\text { pany } \\
* * * * * * * *\end{array}$ & I00.000.000 & $\begin{array}{l}\text { Joint Ven- } \\
\text { ture }\end{array}$ & $\begin{array}{l}\text { Infraestru- } \\
\text { tura }\end{array}$ & $\begin{array}{l}\text { Central } \\
\text { SOE }\end{array}$ & $\begin{array}{l}\text { Busca de } \\
\text { mercado }\end{array}$ \\
\hline
\end{tabular}

* “Compra de 40\% das operaçôes brasileiras da empresa espanhola REPSOL” (Oliveira, A., 20I2, p. 209). ** "Aquisição de 40\% da exploração do Campo de petróleo offshore Peregrino (Bacia de Campos)" (Oliveira, A., 20I2, p. 209).

*** "Instalaçáo de fábrica utilizando a marca KASINSKI" (Oliveira, 20I2, p. 210).

**** "Instalação de siderúrgica, com 70\% de participação da Wisco na joint venture (Porto do Açú - São João da Barra)" (Oliveira, A. 2012, p. 210).

***** "Fabricação de 34 trens para o governo do estado do Rio de Janeiro. O valor será investido na aquisiçáo de maquinário e modernização de planta já existente. A previsão é alcançar 2.500 trabalhadores" (Oliveira A., 2OI2, p. 2II).

****** “30\% dos ativos da Galp no Brasil” (Oliveira, A., 20I2, p. 20II). 
******* "As empresas chinesas CNPC e CNOOC arremataram, em conjunto com a anglo-holandesa Shell, a francesa Total e a brasileira Petrobras, a concessão para exploração de petróleo e gás no Campo de Libra, no pré-sal da Bacia de Campos" (CEBC, 20I4, p. I6).

******** "A State Grid Brazil Holding venceu o leiláo realizado pela Agência Nacional de Energia Elétrica (ANEEL) para a construção da segunda linha de transmissão de Belo Monte. A linha reforçará o escoamento da produção da energia produzida na hidrelétrica até o Sudeste. [...] O investimento previsto é de $\mathrm{R} \$ 7$ bilhóes e as obras serão realizadas em cinco estados: Pará, Tocantins, Goiás, Minas Gerais e Rio de Janeiro" (CEBC, 20I6, p. 28). Entretanto, foram confirmados US\$2.095.000,00 em investimentos cujos projetos contemplaram os referidos estados (CEBC, 2016, p. 30).

"A empresa China Communications Construction Company (CCCC) acertou a aquisição de $80 \%$ do capital da construtora brasileira Concremat Engenharia no valor de R\$350 milhóes. O grupo chinês tem interesses em projetos de infraestrutura, equipamentos pesados e serviços de dragagem no Brasil, onde pretende investir US $\$$ I bilhão no médio prazo. A Concremat confirmou ter assinado um acordo preliminar, com os termos e condiçóes a serem definidos posteriormente" (CEBC, 20I7, p. 24).

Fonte: Oliveira, 20I2 e CEBC, 2013, 2014, 2015, 2016 e 2017 - tabela elaborada pelo autor.

Outro aspecto que pode ser observado na estrutura de propriedade das empresas é o fato de que, entre os dez projetos chineses realizados no estado do Rio de Janeiro, apenas dois foram feitos por empresas privadas - um no setor automotivo e outro no setor de informática. Enquanto os investimentos realizados por empresas estatais chinesas correspondem a oito projetos (gráfico Io). Entre os oito projetos realizados por estatais chinesas, cinco estão relacionados ao setor de energia, destacadamente, no segmento óleo e gás - que abrange quatro deles. Enquanto os outros três contemplam os setores siderúrgico, ferroviário e de infraestrutura.

Gráfico Io - Número de projetos chineses no território fluminense por estrutura de propriedade das empresas - 2010-2016

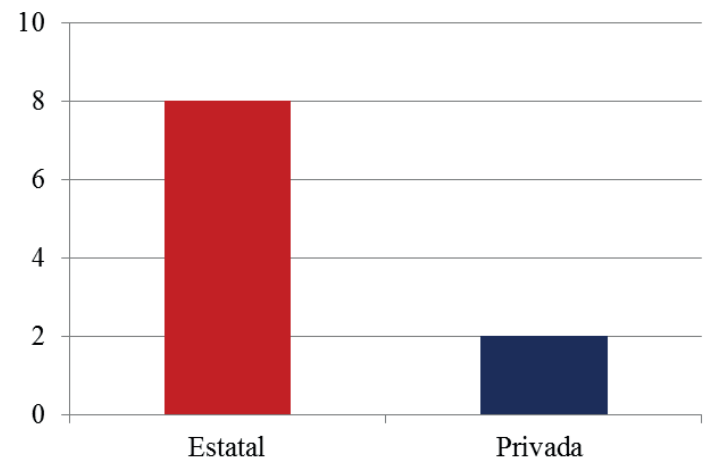

Fonte: $\mathrm{O}$ autor, 2017. 
Com efeito, o setor de energia náo corresponde apenas ao maior número de projetos, mas abrange o maior volume de capital investido pelas estatais chinesas no estado do Rio de Janeiro, compreendendo, aproximadamente, a US \$ I8, o bilhóes, ou seja, 82,4\% dos investimentos realizados no território fluminense, entre 20I0-20I6. Por outro lado, os investimentos nos setores de informática, automotivo, de infraestrutura, ferroviário e siderúrgico compreendem tanto os menores volumes em investimentos quanto apenas um projeto em cada um desses setores, assim como os menores percentuais, conforme evidencia o gráfico II.

Gráfico II - Investimentos chineses no estado do Rio de Janeiro: distribuição por setores (\%)

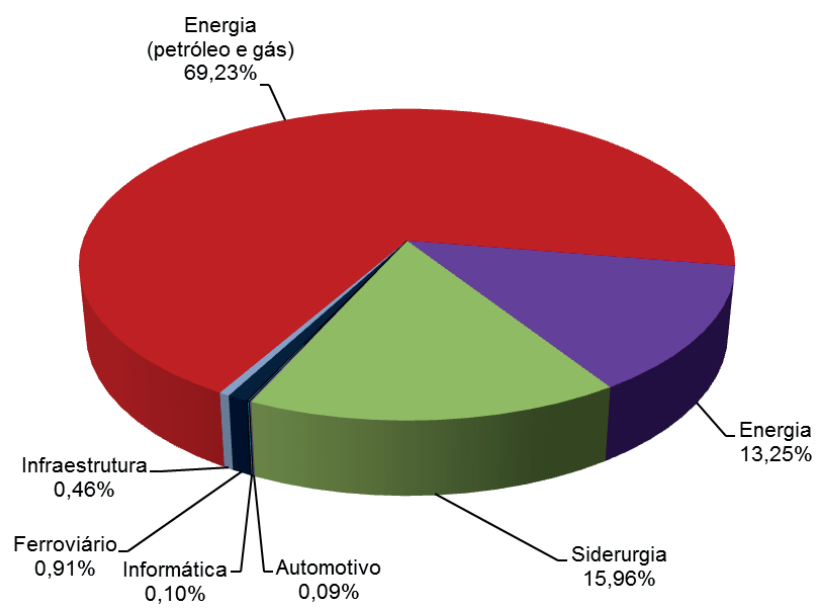

Fonte: CEBC (20I7) - gráfico elaborado pelo autor.

\section{Consideraçóes finais}

Compreende-se, a partir do presente estudo, que o território fluminense, ao longo do século XX, apresentou uma trajetória caracterizada pela diminuição de sua participação na produção industrial brasileira e redução de sua contribuição no PIB nacional. Tendo que aguardar a década de 1990 para assistir a um conjunto de mudanças atreladas à implantação de novas atividades produtivas, a realização de novos investimentos em infraestrutura e as alteraçóes nas bases de suas economias regionais que, por conseguinte, desencadearam o processo de reestruturação produtiva do território. 
$\mathrm{Na}$ atual fase do processo de globalização e intensificação da circulação de capital, o estado do Rio de Janeiro, como recipiendário de investimentos, assistiu, mais recentemente, ao influxo do capital sínico em seu território. Assim, este, entre os anos de 2007 e 2016, foi o destino de, aproximadamente, US $\$ 2$ I,9 bilhôes de investimentos chineses realizados no Brasil, o que corresponde a $45 \%$, dos US\$46, I bilhóes, sob a forma de IED oriundo da República Popular da China confirmados no país, entre 2007 e 2016.

$\mathrm{O}$ ingresso dos investimentos chineses no Brasil, no recorte temporal mencionado, equivaleu à implantação de 88 projetos. Entre estes, 78 foram realizados em diferentes unidades federativas do país, enquanto, no território fluminense, foram dez, concentrando-se no setor de energia, apesar de outros setores como o siderúrgico, o de infraestrutura, o ferroviário, o de informática e o automotivo também se apresentarem como receptores desse montante de capital.

Nota-se, ainda, que a estrutura da propriedade dos investimentos chineses é predominantemente estatal, dada a atuação, em oito desses projetos, realizada por grandes corporaçôes chinesas, como por exemplo: a Sinopec Repsol Brasil, a Sinochem Statoil, a Wuhan Iron Stell Group Co., a China Northern Railway, a China National Petroleum Corporation, a China National Offshore Oil Corporation, a State Grid, a China Communications Construction Company. Enquanto os menores volumes de capital investido no estado correspondem à implantação de dois projetos de empresas privadas chinesas nos setores automotivo e de informática, por meio da atuação, respectivamente, da CR Zong-Shen e da Qihoo, cujo determinante do investimento foi a busca por mercado, as grandes corporaçóes chinesas mencionadas, que se concentram, destacadamente, nos setores de energia, siderurgia, infraestrutura e ferroviário, têm a busca por recursos como principal determinante dos seus investimentos no território fluminense, embora a busca por mercado se projete como determinante dos investimentos realizados pelas empresas China Northern Railway e State Grid.

\section{Referências}

ALVES, A. G. de M. P. "As relaçôes de investimentos diretos entre a China e os países de seu entorno". In (org.). Os BRICS e seus vizinhos: investimento direto estrangeiro. Brasília: IPEA, 2014.

ANDREWS, Christina W. "Da década perdida à reforma gerencial: 1980-1998". In e BARIAN, Edson (orgs.). Administração pública no Brasil: breve história política. São Paulo: Editora Unifesp, 2010, pp. 85-II8. 
BUCKLEY, P. J. et al. "Historic and emergent trends in chinese outward direct investment". Foreign direct investment, China and the world economy. Palgrave Macmillan, 2010.

CASTRO, Lavinia Barros de. "Privatização, abertura e desindexação: a primeira metade dos anos I990 (I990-I994)”. In GIAMBAGI, F. et al. (orgs.). Economia brasileira contemporânea (1945-2015). 3 ed. - Rio de Janeiro: Elsevier, 2016.

CEBC - Conselho Empresarial Brasil-China. Investimentos chineses no Brasil: uma nova fase da relação Brasil-China. Rio de Janeiro, 20II.

. Uma análise dos investimentos chineses no Brasil: 2007-20I2. Rio de Janeiro, 2013.

. Boletim de investimentos chineses no Brasil (2012-2013). Rio de Janeiro, 2014.

. Oportunidades de comércio e investimento na China para setores selecionados. Rio de Janeiro, 20I5.

. Investimentos chineses no Brasil: 2014-2015. Rio de Janeiro, 2016.

. Investimentos chineses no Brasil: 20I6. Rio de Janeiro, 2017.

CEPAL - Comissão Econômica para a América Latina e o Caribe. Documento informativo La inversión Extranjera Directa en América Latina y el Caribe. Disponível em: http://repositorio.cepal.org bitstream handle II362420234Si70043I_es.pdf. Acesso em: or set. 2017.

GIAMBIAGI, Fabio. "Estabilização, reformas e desequilíbrios macroeconômicos: os anos FHC (1995-2002)”. In et al. (orgs.). Economia brasileira contemporânea (1945-2015). 3 ed. Rio de Janeiro: Elsevier, 2016.

IPEA - Insituto de Pesquisa Econômica Aplicada. "Internacionalização das empresas chinesas: as prioridades do investimento direto chinês no mundo". Comunicados do IPEA, n. 84, 201 .

KISSINGER, H. Sobre a China. Rio de Janeiro: Objetiva, 2oII.

LACERDA, Antônio Corrêa de. "Notas sobre as características e o perfil dos fluxos recentes de investimentos diretos estrangeiros na economia brasileira”. In VEIGA, Pedro da Motta (org.). O Brasil e os desafios da globalização. Rio de Janeiro: Relume-Dumará/São Paulo: SOBEET, 2000, pp. 193-207.

MELO, H. P. “A trajetória da industrialização do Rio de Janeiro”. In FREIRE, A. et al. (orgs.) Um Estado em questão: os 25 anos do Rio de Janeiro. Rio de Janeiro: FGV, 200I, pp. 219-48.

MIRANDA, José Carlos e TAVARES, Maria da C. "Brasil: estratégias de conglomeração". In FIORI, José Luís (org.). Estados e moedas no desenvolvimento das naçôes. Petrópolis, RJ: Vozes, I999, pp. 327-50.

OLIVEIRA, A. L. S. de. O investimento direto das empresas chinesas no Brasil: um estudo exploratório (dissertação). UFRJ, 2012.

OLIVEIRA, F. J. G. "Políticas territoriais e integração do 'novo' território do estado do Rio de Janeiro”. In EGLER, T. T. C e TAVARES, H. M. (orgs.). Politica pública, rede social e território. Rio de Janeiro: Letra Capital, 2012. 
OLIVEIRA, H. A. de. Brasil e China: cooperação Sul-Sul e parceria estratégica. Belo Horizonte: Fino Traço, 2012.

SANTOS, M. "O retorno do território”. In Da totalidade ao lugar. São Paulo: Edusp, 20I2, pp. I37-44.

SILVA, R. D. Indústria e desenvolvimento regional no Rio de Janeiro. Rio de Janeiro: FGV, 2012.

SÖDERSTEN, B. Economia internacional. Rio de Janeiro: Interciência, I979.

SOJA, Edward. "Uma concepção materialista da espacialidade". In BECKER, Berta et al. Abordagens politicas da espacialidade. Rio de Janeiro: UFRJ- Departamento de Geografia/ Programa de Pós-Graduação, I983.

TENÓRIO, Fernando G. e SARAIVA, Enrique J. "Escorços sobre gestão pública e gestão social”. In MARTINS, Paulo E. Matos e PIERANTI, Octavio Penna (orgs.). Estado e gestão pública: visóes do Brasil contemporâneo. 2 ed. Rio de Janeiro: FGV, 2006.

TERRA, D. C. et al. "A reestruturação econômica e territorial do Norte Fluminense". In MONIÉ. F. e BINSZTOK, J. (orgs.). Rio de Janeiro: Mauad, 2012. 